\title{
Angiolymphoid hyperplasia with eosinophilia versus Kimura's disease: a case report and a clinical and histopathological comparison*
}

\author{
Julien Totti de Bastos ${ }^{1}$ \\ Priscila Mara Chaves e Silva ${ }^{1}$ \\ Flávia de Freire Cassia ${ }^{1}$
}

\author{
Camila Roos Mariano da Rocha ${ }^{1}$ \\ Bruno Messias Pires de Freitas ${ }^{1}$ \\ João Carlos Regazzi Avelleira ${ }^{1}$
}

DOI: http:/ / dx.doi.org/10.1590/abd1806-4841.20175318

\begin{abstract}
Angiolymphoid hyperplasia with eosinophilia is a rare and benign vascular tumor whose etiology remains uncertain. It clinically presents itself by angiomatous papules or nodules located on the head and neck. Many controversies in the literature are found in relation to angiolymphoid hyperplasia with eosinophilia and Kimura's disease - its main differential diagnosis - due to their clinical and histopathological similarities. However, currently, most studies agree that they are distinct diseases. The present case illustrates a characteristic description of angiolymphoid hyperplasia with eosinophilia and also highlights the main differences with Kimura's disease.
\end{abstract}

Keywords: Angiolymphoid hyperplasia with eosinophilia; Cutaneous neoplasms; Eosinophilia

\section{INTRODUCTION}

Angiolymphoid hyperplasia with eosinophilia (ALHE) is a rare vascular tumor first described by Wells \& Whimster in 1969. Its etiology remains uncertain. It is characterized by papules or nodules of angiomatoid aspect, predominantly located on the head, especially around the ears. ${ }^{1}$

The relationship between the disorder known as Kimura's disease in the Eastern literature and ALHE, described in Western literature, has always been a subject of debate. Because of their similarities, these two conditions were initially considered two outcomes of the same disease. ${ }^{2-4}$ Although recent articles have established consistent differentiation criteria, there are still differences in the understanding of the two entities.

This article describes a typical clinical case of ALHE and provides a brief discussion of the differences from its main differential diagnosis, Kimura's disease.

\section{CASE REPORT}

A 68-year-old female patient reported nodular erythematous lesions on the scalp, with occasional itching and bleeding. The lesion appeared 10 years before and showed progressive growth during this period. She denied trauma at the site.

Her medical history revealed hypertension and no other comorbidities or relevant diseases in the family.
Dermatological examination revealed two lesions in the occipital region of approximately $1 \mathrm{~cm}$ in diameter each, of angiomatous aspect and smooth surface (Figures 1A and 1B). Blood count and renal function were both normal without eosinophilia. Biopsy of the lesion showed groups of thick-walled vessels with prominent endothelium and frequent vacuoles in endothelial cells (Figures 2A and 2B). The vessels formed lobes surrounded by lymphocytic infiltrate with frequent eosinophils (Figure 2C), confirming the diagnosis of ALHE.

We recommended surgical excision of the lesion. Nine months after the surgery, in a follow-up visit, the patient presented with four new nodular lesions on the scalp, similar to the initial lesion, but smaller and asymptomatic; we opted for expectant management. The initial lesion showed no recurrence.

\section{DISCUSSION}

ALHE is a rare benign tumor which is clinically manifested by the presence of dermal papules or nodules measuring about $2-3 \mathrm{~cm}$, varying in color from light brown to pink. The lesions occur preferentially on the face, scalp, auricular region, and neck. There seems to be a higher incidence in females and lesions are more common in patients aged $20-50$ years. ${ }^{2.4}$

Received on 30.10 .2015

Approved by the Advisory Board and accepted for publication on 15.02.2016

* Work performed at Hospital Federal da Lagoa - Rio de Janeiro (RJ), Brazil.

Financial support: none.

Conflict of interest: none.

1 Department of Dermatology at Hospital Federal da Lagoa - Rio de Janeiro (RJ), Brazil.

(C2017 by Anais Brasileiros de Dermatologia 

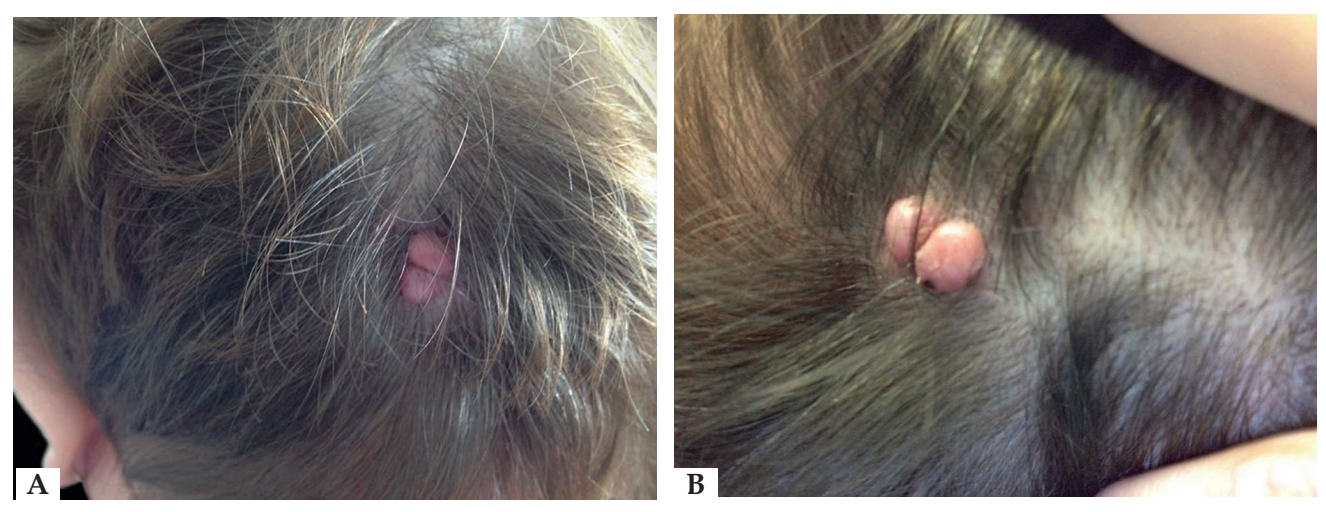

Figure 1:

A. Nodular lesion of angiomatous aspect in the occipital region. B. Higher magnification of the occipital region: Pinkish bilobate nodule of angiomatous aspect
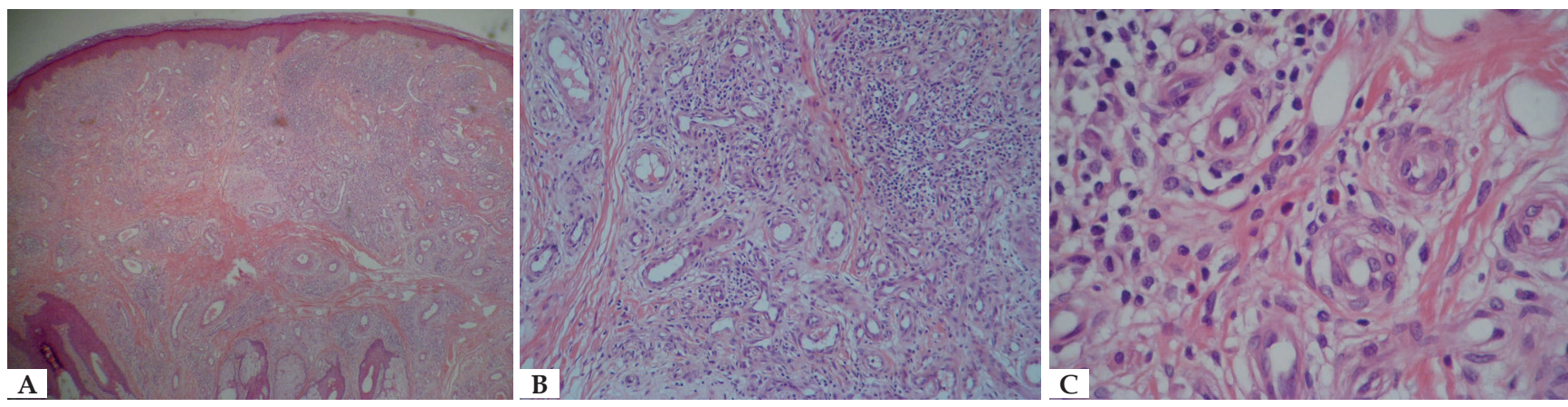

Figure 2: A. Diffuse inflammatory infiltrate and presence of vascular proliferation in the dermis (Hematoxylin \& eosin 40x). B. Capillaries with prominent endothelium and vacuoles in endothelial cells (Hematoxylin \& eosin 100x). C. Higher magnification shows eosinophils in the inflammatory infiltrate (Hematoxylin \& eosin 400x)

Its pathogenesis remains unknown. Some authors believe that the damage would be due to a vascular tumor. Others claim that they could represent a reaction to vascular tissue injuries such as skin trauma, infections (HTLV or herpes virus 8 ), or hormonal imbalance. ${ }^{5-7}$ Some recent studies tend to consider it as a vascular malformation secondary to a subcutaneous arteriovenous shunt, but the hypothesis most widely accepted is that it is a reactive vascular hyperplasia to various stimuli. ${ }^{1,4}$

Its main differential diagnosis is Kimura's disease, but other diseases such as insect bite reaction, pyogenic granuloma, cylindroma, angiosarcoma, hemangioma, or skin lymphocitoma may clinically resemble ALHE. ${ }^{2-9}$

Initially described by Kim and Szeto in 1937, Kimura's disease became better known after a systematic description provided by Kimura in 1948. Since then, due to the similarity in the expression of the lesion site, to the variety of histological findings, to reports on the coexistence of the two entities in the same patient, and especially due to the rarity of these two diseases, many authors cite them as manifestations of the same disease. ${ }^{5}$ However, nowadays, most of the studies agree to consider them two distinct entities. ${ }^{1,2,4}$

Kimura's disease occurs mainly in young men of Asian descent with one or multiple asymptomatic masses involving the subcutaneous tissue and salivary glands. It is often accompanied by regional lymph node involvement, peripheral blood eosinophilia, and elevated IgE. In contrast, ALHE occurs predominantly in middle-aged women, presenting itself with multiple small papules or erythematous nodules associated with itching. Nephrotic syndrome, such as membranous glomerulonephritis or mesangioproliferative, is more related to Kimura's disease. Systemic manifestations are rarely found in ALHE. ${ }^{2-9}$

Histopathology of Kimura's disease demonstrates a marked follicular hyperplasia with follicles surrounded by a large number of eosinophils, lymphocytes, and mast cells. Lymphoid follicles are hyperplastic and contain prominent germinal centers. Fibrosis, sclerosis, and vascular proliferation are also present. . $^{2,45}$ In contrast, histopathology of ALHE shows an abnormal vascular proliferation and diffuse lymphocytic infiltrates with eosinophils. The vascular component is formed by capillaries clustered around arterial or venous vessels, dilated and atypical. These capillaries have a protruded endothelium with rounded and sometimes polygonal nuclei. One or more cytoplasmic vacuoles can be seen in endothelial cells. Lymphoid follicles are rare or absent in most cases. . $^{1,2,4}$

The treatment of choice for ALHE is surgical excision, but relapse is common. Cryotherapy, local radiotherapy, topical or intralesional corticosteroids, imiquimod, acitretin, and laseterapia (dye laser, $\mathrm{CO}_{2}$ laser) are also reported as possible treatments with varying success levels. There are reported cases of spontaneous regression. ${ }^{4-10}$

In the present case, we also observed that the patient had small angiomatous papules on the scalp, clinical lesions character- 
istic of ALHE. Epidemiology also fits with other studies. Clinical and epidemiological features allow the easy differentiation of ALHE compared to Kimura's disease.

Histopathology revealed a diffuse inflammatory infiltrate, presence of abundant vascular proliferation with vacuoles in endothelial cells and eosinophil infiltration, featuring a predominantly vascular process. With different characteristics, Kimura's disease shows lymphoid follicles and a higher mean number of eosinophils, without the cytoplasmic vacuoles found in ALHE.

Although there are some disagreement in the literature on ALHE and Kimura's disease, we believe that with the present case report and the data provided by the literature, many distinctions can be made between the two diseases in all the aspects mentioned with clinical, epidemiological, and histopathological changes.

\section{REFERENCES}

1. Quattrocchi CM, Jankovic R, Jacquier M, Sánchez A, Bergero A, Bussy RAF. Hiperplasia angiolinfoide con eosinofilia: reporte de un caso. Arch Argent Dermatol. 2012;62:189-92

2. Briggs PL. Doença de Kimura não é hiperplasia angiolinfóide com eosinofilia: correlação clínicopatológica com revisão da literatura e definição de critérios diagnósticos. An Bras Dermatol. 2006;81:167-73.

3. Kede MPV, Scotelaro Alves MFG, Ramos e Silva M. Hiperplasia angiolinfóide com eosinofilia: relato de dois casos. An Bras Dermatol.1993;68:283-85.

4. Nogueira A, Acccioly Filho JW, Castro MCR, Maceira JP, Ramos e Silva M. Hiperplasia angiolinfóide com eosinofilia - relato de dois casos. An Bras Dermatol. 2003;78:79-85

5. Chong WS, Thomas A, Goh CL. Kimura's disease and angiolymphoid hyperplasia with eosinophilia: two disease entities in the same patient. Case report and review of the literature. Int J Dermatol. 2006;45:139-45.

6. Reddy PK, Prasad AL, Sumathy TK, Shivaswamy KN, Ranganathan C. An overlap of angiolymphoid hyperplasia with eosinophilia and Kimura's disease: successful treatment of skin lesion with cryotherapy. Indian J Dermatol. 2015;60:216.

7. Ahmad SM, Wani GM, Khursheed B, Qayoom S. Angiolymphoid hyperplasia with eosionophilia mimicking cylindromas: a rare case report. Indian J Dermatol. 2014:59:423

8. Sun QF, Xu DZ, Pan SH, Ding JG, Xue ZQ, Miao CS, et al. Kimura disease: review of the literature. Intern Med J. 2008;38:668-72.

9. Palomo Arellanoi A, Díaz Sánchez E, Cervigón González I, Torres Iglesias LM. Hiperplasia angiolinfoide com eosinofilia. Un caso clínico y revisión de la literatura española. Med Cutan Iber Lat Am. 2009;37:197-200.

10. Esteves P, Barbalho M, Lima T, Quintella L, Niemeyer-Corbellini JP, Ramos-ESilva M. Angiolymphoid hyperplasia with eosinophilia: A Case Report. Case Rep Dermatol. 2015;7:113-6.
MAILING ADDRESS:

Julien Totti de Bastos

Rua Jardim Botânico, 501 - Jardim Botânico

22470-050 - Rio de Janeiro - RJ

Brazil

E-mail:jutotti@hotmail.com

How to cite this article: Bastos JT, Rocha CRM, Silva PMC, Freitas BMP, Avelleira JCR, Cassia FF. Angiolymphoid hyperplasia with eosinophilia versus Kimura's disease: a case report and a clinical and histopathological comparison. An Bras Dermatol. 2017;92(3):392-4. 